\title{
Consumer Behavior Analysis with Respect to Life Insurance Sector in India
}

\author{
Aman Damani ${ }^{1}$, Swati Bhatnagar ${ }^{2}$ \\ MBA Scholar, Amity Business School, Amity University Uttar Pradesh, Sector 125, Noida - 201303, Uttar Pradesh, India \\ Assistant Professor, Department of Marketing \& Sales, Amity Business School, Amity University Uttar Pradesh, Sector 125, Noida - \\ 201303, Uttar Pradesh, India
}

\begin{abstract}
This research paper highlights consumer buying behavior with respect to life insurance policies and at the same time profiles the customers into distinct demographic segments such as age, income etc. Life Insurance sector is one of the fastest developing areas in India since year 2000 as Government allowed Private players and FDI up to 26\%. Most recent Cabinet endorsed a proposition to grow it to 49\%. Extra security in India was nationalized by joining Life Insurance Corporation (LIC) in 1956 and around then all private disaster protection organizations were assumed control by LIC. In year 1993, the Government named RN Malhotra Committee to set out a guide for privatization of the disaster protection segment. While the trustees displayed its report in 1994, it took an extra six years previously the demonstration was passed in the year 2000.In that same year there was arrangement of new protection controller - IRDA framed which began offering licenses to private life coverage organizations.
\end{abstract}

\section{Introduction}

Consumer Behaviour is the investigation of people, gatherings, or associations and every one of the exercises related with the buy, utilize and transfer of merchandise and enterprises, including the buyer's passionate, mental and behavioral reactions that go before or take after these exercises. Customer conduct developed in the 50s as a particular sub-teach in the showcasing region. Buyer conduct is a between disciplinary sociology that mixes components from brain science, human science, social human sciences, ethnography, advertising and financial aspects, particularly behavioral financial matters. It looks at how feelings, mentalities and inclinations influence purchasing conduct. Qualities of individual customers, for example, socioeconomics, identity ways of life and behavioral factors, for example, utilization rates, use event, unwaveringness, mark promotion, eagerness to give referrals, trying to comprehend individuals' needs and utilization are altogether examined in formal investigations of buyer conduct. The investigation of shopper conduct additionally explores the impacts, on the buyer, from gatherings, for example, family, companions, sports, reference gatherings, and society when all is said in done. Disaster protection is an agreement between a protection holder and a safety net provider, where the guarantor guarantees to pay a specific total of sum for a top notch which is been paid safeguarded on the demise of a protection holder.

\subsection{Objective of the study}

The research is undertaken to find out-

- Consumer buying behavior

- Consumer profiling

\subsection{Data Collection}

The research is based on both primary and secondary data. The essential information is gathered from an example size of 42 respondents between the age of 20 to 55 crosswise over Delhi NCR. The optional information is gathered from different research diaries, periodicals and research papers. A portion of the information is additionally taken from the web

\subsection{Research Methodology}

The analysis of data is exploratory in nature. A qualitative, structured questionnaire is used as a tool to conduct the survey to gain an understanding of consumer behavior of customer with respect to life insurance sector in India.

\subsection{Limitations of the study}

- Research is based on both primary and secondary data.

- The example estimate is 42 , the information won't not give the precise outcomes.

- The perspectives of the shoppers may not be 100 percent genuine.

- Time requirement.

- All the information, which is taken, is based on primary and secondary data that has its own limitations.

\section{Interpretation}

\begin{tabular}{|c|c|c|c|c|}
\hline S. No. & \multicolumn{2}{|c|}{ Particulars } & Respondents & Percentage \\
\hline 1 & \multirow{2}{*}{ Age } & Below 28 & 18 & $42.9 \%$ \\
\cline { 3 - 5 } & & $28-35$ & 12 & $28.6 \%$ \\
\cline { 3 - 5 } & & Above 35 & 12 & $28.6 \%$ \\
\hline 2 & \multirow{2}{*}{ Marital status } & Married & 23 & $54.8 \%$ \\
\cline { 3 - 5 } & & Single & 19 & $45.2 \%$ \\
\hline \multirow{3}{*}{3} & \multirow{2}{*}{ Income } & Below 1.5 lacs & 11 & $26.2 \%$ \\
\cline { 4 - 5 } & & $1.5-3$ lacs & 10 & $23.8 \%$ \\
\cline { 3 - 5 } & & 3-5 lacs & 6 & $14.3 \%$ \\
\cline { 3 - 5 } & & Above 5 lacs & 15 & $35.7 \%$ \\
\hline
\end{tabular}


International Journal of Science and Research (IJSR)

ISSN (Online): 2319-7064

Index Copernicus Value (2016): 79.57 | Impact Factor (2015): 6.391

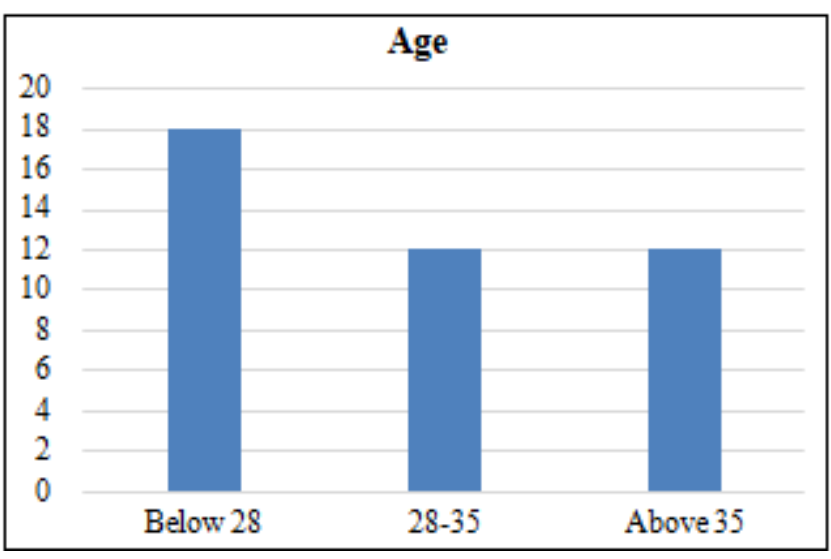

The bar graph above illustrates the age group of respondents. A large portion of respondents is below 28 years of age and respondents 28-35 and above 35 are equal.

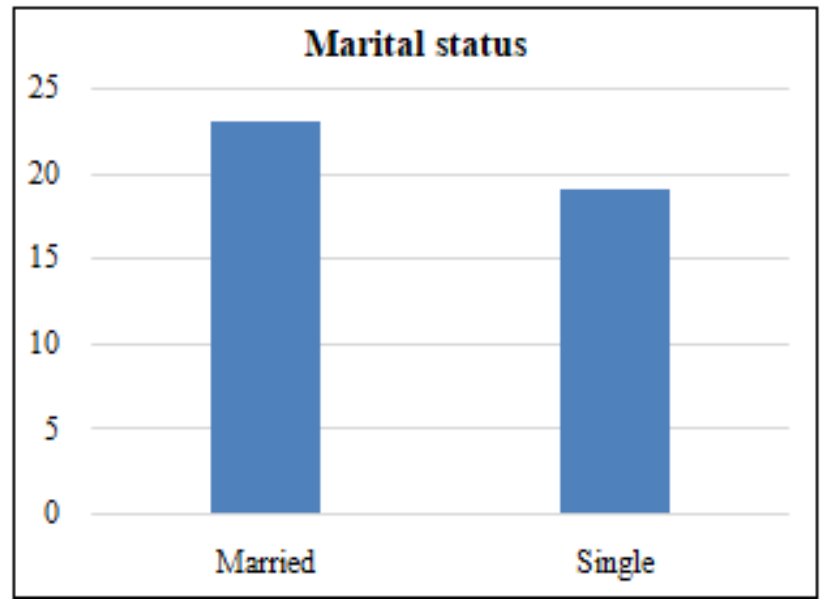

This bar graph illustrates the marital status of respondents. A majority of respondents are married and minorities of respondents are single.

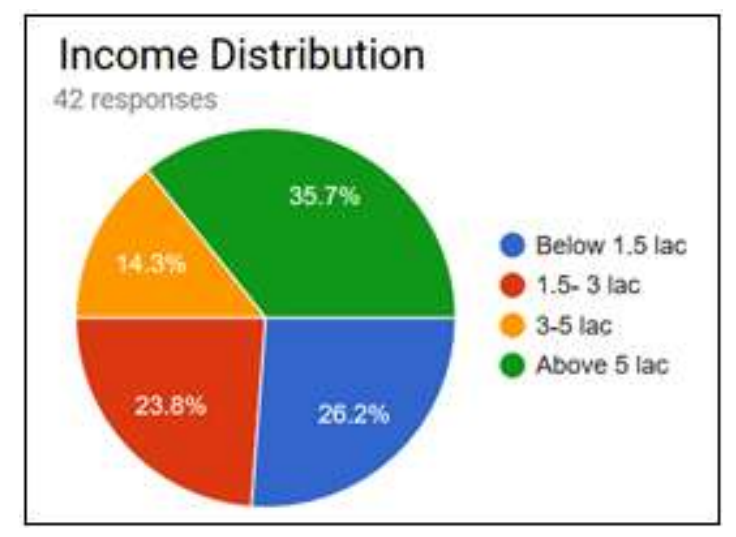

The pie chart above illustrates income of respondents. A significant number of respondents earn above 5 lacs. A small number of respondents earn below 1.5 lacs and are between 1.5- 3 lacs and small majority of respondents earn 3-5 lacs.

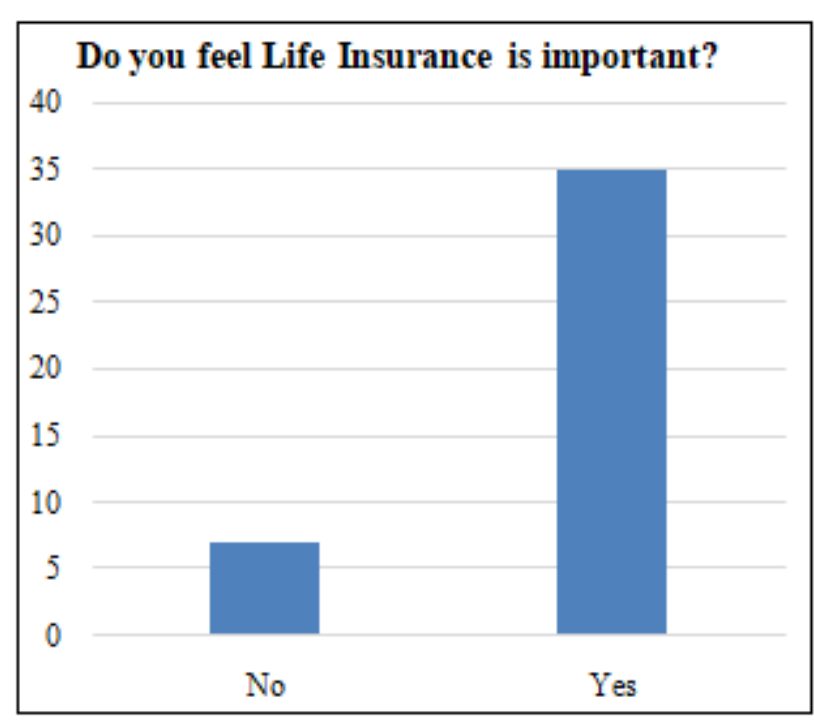

The bar graph above illustrates what respondents think about life insurance policy. A majority of respondents think life insurance is important and minority of respondents feel life insurance is not important.

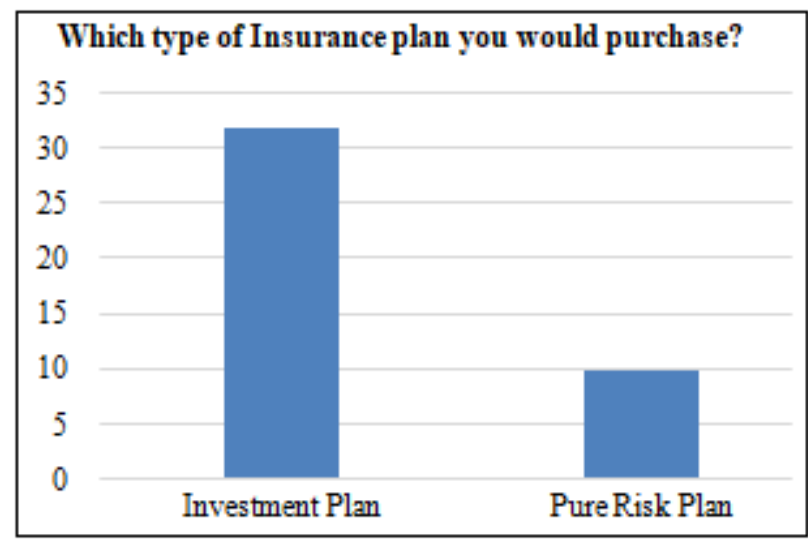

The above bar graph illustrates the plans which respondents would buy. The majority of respondents responded that they would opt for investment plan. Minority of respondents responded that they would go for pure risk plan.

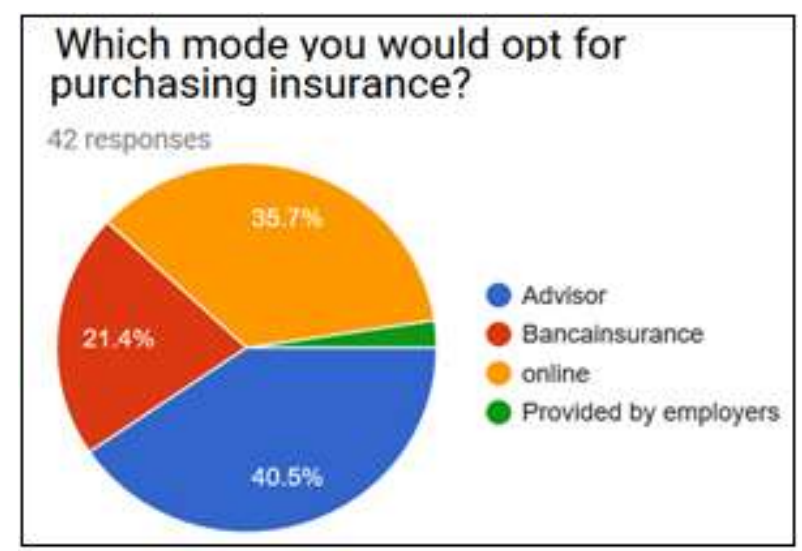

The pie chart above illustrates the medium which respondents use to buy life insurance. Majority of respondents will opt medium of advisor. A small number of respondents would opt for bancainsurance and online as medium to buy life insurance. Small minority would opt insurance which is been provided by employees.

\title{
Volume 6 Issue 12, December 2017
}

\author{
www.ijsr.net
}


International Journal of Science and Research (IJSR)

ISSN (Online): 2319-7064

Index Copernicus Value (2016): 79.57 | Impact Factor (2015): 6.391

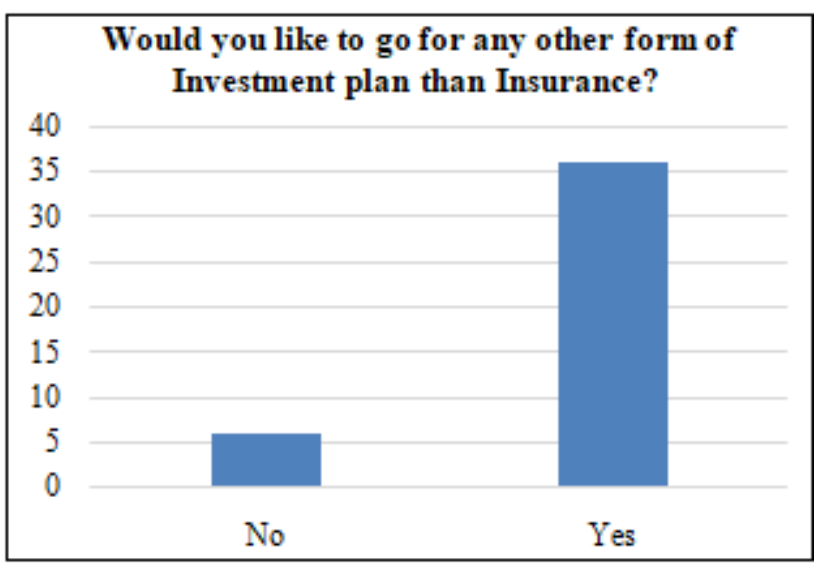

The above bar graph illustrates would respondents will like to go for any other form of investment plan than life insurance. Majority of respondents responded that they will go for any other form of investments. Minority of respondents responded that they wouldn't opt any other form of investment plans than insurance.

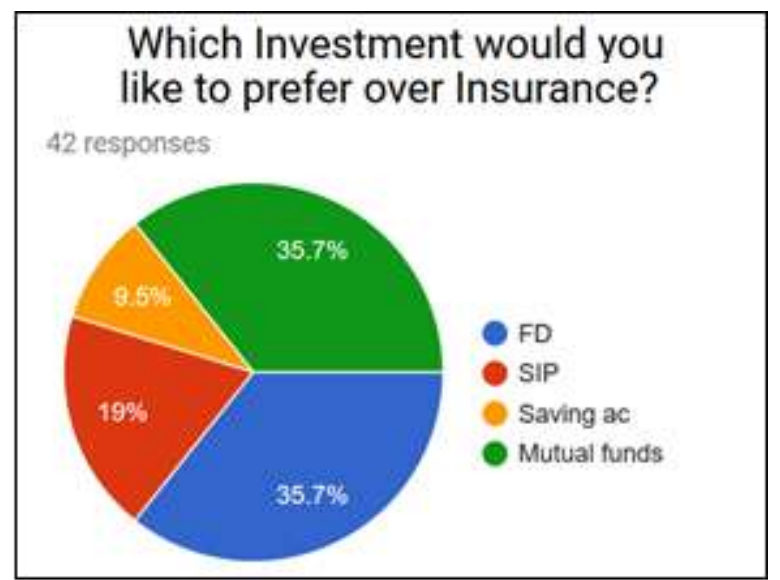

The above pie chart illustrates which investment would respondents prefer over insurance. Majority of respondents responded that they would either opt for FD or Mutual funds. Minority of respondents responded that they would either go for SIP or savings.

\section{With increase in Income would you like to opt for more insurance policies?}

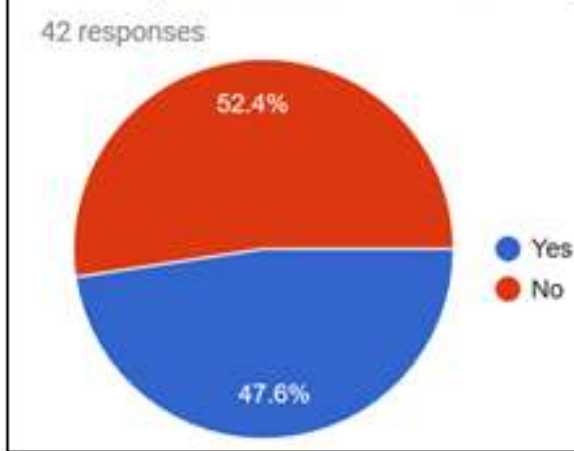

The above pie chart illustrates with increase in income would respondents like to opt for more insurance policies. A majority of respondents responded that they won't opt for more insurance policies and minority of respondents responded that they would opt for more insurance policies.

\section{Findings}

- Most of the respondents think life Insurance is important

- Most of the respondents would like to go for other form of investment than Insurance.

- Most of the respondents would either prefer FD or Mutual funds over Insurance.

- Most of the respondents won't opt for more insurance with increase in their Income.

\section{Conclusion}

In current market situation, there are exceptionally visit changes in speculation propensities for Indian customers. Each individual has their own perspectives towards different sorts of speculation designs. This examination paper work is centered around purchaser's perspectives on interest in Life Insurance Services. The goal of this examination paper is to assess buyer conduct towards extra security part and purchaser profiling. Customer's view towards Life Insurance division is certain. Still a couple of exercises are required for creating Insurance part. Protection industry needs to continue. A ton of chances are as yet holding up.

\section{Declaration}

Title of Research Paper: "Consumer behavior analysis with respect to life insurance sector in India". Author declare that the work is presented for assessment in Independent Study \& Research is his own, that it has not previously been presented for another assessment and that his debts (for words, data, arguments and ideas) have been appropriately acknowledged. That the work conforms to the guidelines for presentation and style set out in the relevant documentation.

\section{References}

[1] www.irda.com

[2] www.insuranceindia.com

[3] www.conind.com 